2015-06

Real-Time Hallucination Simulation and Sonification through User-Led

Development of an iPad Augmented Reality Performance

\author{
Kirke, Alexis
}

http://hdl.handle.net/10026.1/6631

10.1162/leon_a_00812

Leonardo

MIT Press - Journals

All content in PEARL is protected by copyright law. Author manuscripts are made available in accordance with publisher policies. Please cite only the published version using the details provided on the item record or document. In the absence of an open licence (e.g. Creative Commons), permissions for further reuse of content should be sought from the publisher or author. 


\title{
Real-Time Hallucination Simulation and Sonification through User-Led Development of an iPad Augmented Reality Performance
}

\author{
ALEXIS KIRKE, JOEL EATON AND EDUARDO MIRANDA
}

The simulation of visual hallucinations has multiple applications. The authors present a new approach to hallucination simulation, initially developed for a performance, that proved to have uses for individuals suffering from certain types of hallucinations. The system, originally developed with a focus on the visual symptoms of palinopsia experienced by the lead author, allows real-time visual expression using augmented reality via an iPad. It also allows the hallucinations to be converted into sound through visuals sonification. Although no formal experimentation was conducted, the authors report on a number of unsolicited informal responses to the simulator from palinopsia sufferers and the Palinopsia Foundation.

Palinopsia is a visual symptom involving trails in the visual field [1] (Fig. 1). In addition to this symptom, palinopsia can lead to very strong afterimages [2]. These are similar to when one stares at the sun and continues to see it after looking away; however, they can be much stronger for Palinopsics and can be caused by objects that are not particularly bright-a door, for example. One interesting aspect of palinopsia is that it can occur in individuals who show no other visual symptoms. Palinopsia is a set of symptoms rather than a condition. Author and neuroscientist Oliver Sacks has experienced the symptoms of palinopsia [3].

The academic study of palinopsia is still in its early stages. Scientists are divided in their terminology, using alternative terms such as polyopia and visual perseveration [4]. They also have different ideas about the causes of the condition. One possibility is a reduction of the inhibition function in certain neurons in the visual cortex [5]. The undersuppressed random firing of cortical neurons could perhaps explain how

Alexis Kirke (permanent research fellow), Interdisciplinary Centre for Computer Music Research, School of Humanities and Performing Arts, Plymouth University, U.K. Email: <alexis.kirke@plymouth.ac.uk>.

Joel Eaton (research student), Interdisciplinary Centre for Computer Music Research, School of Humanities and Performing Arts, Plymouth University, U.K. Email: <joel.eaton@students.plymouth.ac.uk>

Eduardo Miranda (professor of computer music), Interdisciplinary Centre for Computer Music Research, School of Humanities and Performing Arts, Plymouth University, U.K. Email: <eduardo.miranda@plymouth.ac.uk>

See $<w w w$.mitpressjournals.org/toc/leon/48/3> for supplemental files associated with this issue. the afterimage of a moving object is not cancelled out more firmly and why the evolving patterns seem to come from nowhere. There have also been interesting initial results concerning a common "visual trail rate" of $15-20 \mathrm{~Hz}[6]$.

For some the condition of palinopsia is debilitating; some fail to realize the images are not real. For many it is a lonely condition they are afraid to reveal to anyone. Sacks estimates that up to $90 \%$ of people with the hallucination condition Charles Bonnet syndrome (CBS) - a condition common among people who have gone blind that causes very specific, in some cases cartoon-like, hallucinations-do not mention their hallucinations to others [7]. The lack of understanding of palinopsia could perhaps be remedied by the use of tools that enable palinopsics to express their visual hallucinations more clearly to others. Software that can enable some of these people to express and discuss their visual disturbances with

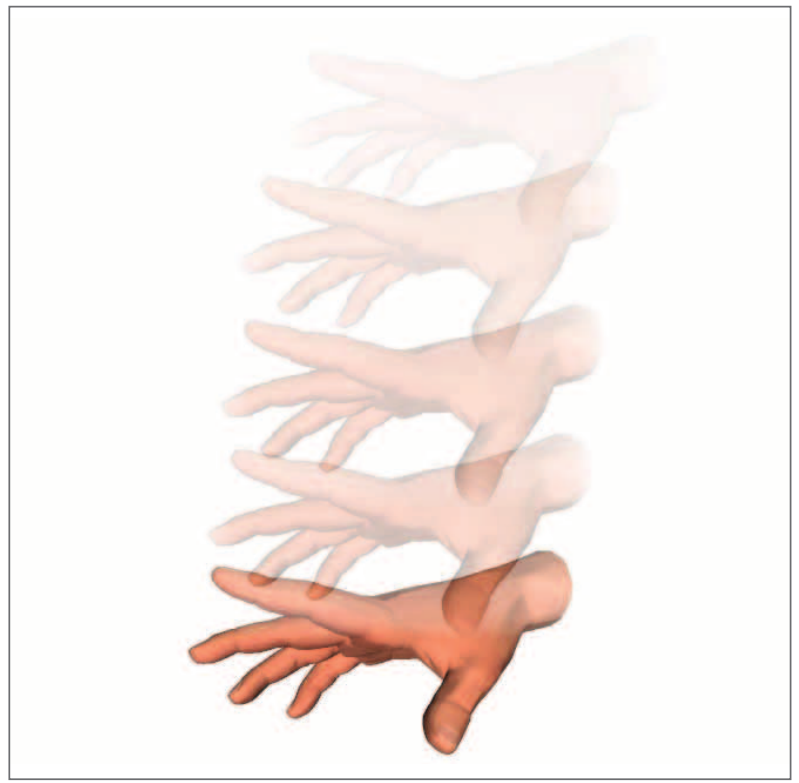

Fig. 1. Rendering visual trails symptomatic of palinopsia. (@ Alexis Kirke) 
a close friend or perhaps a therapist or medical professional may be beneficial. It could help medical professionals and neuroscience researchers gain deeper insight into precisely what their subjects and patients are seeing.

\section{SIMULATORS AND AUGMENTED REALITY}

Static hallucination simulators are used to help people express exactly what hallucinations they have. There has been some work in the use of virtual reality to model hallucinations to help teach people about schizophrenia [8], and the pharmaceutical company Janssen Pharmaceuticals has developed a system for laptop and stereo glasses to simulate hallucinations [9] for training, but neither of these systems is truly interactive or based on real-time augmented reality.

Augmented reality (AR) is a method of combining live camera data on a smartphone or tablet with real-time-generated images, both of which appear on the screen simultaneously [10]. There are many applications available involving $\mathrm{AR}$, including some designed to help rehabilitate people with physical [11] or cognitive [12] disabilities. There are also AR systems to help visually impaired people navigate more easily [13]. Applications that manipulate the visual field to simulate what people are seeing subjectively are less common. Our application, the "Halluciphone," which we discuss in this paper, applies AR in this way.

\section{THE HALLUCIPHONE}

The Halluciphone was originally developed for a performance called Insight. The basic system used in the performance consisted of an iPad with custom software allowing author Alexis Kirke to attempt to represent the hallucinations he experiences. The parameters representing the selected visual hallucinations on the iPad are sent to a laptop computer equipped with Max/MSP software for sonifying the visual effects. There has been previous work on the sonification of visuals $[14,15]$ and also the sonification of medical data $[16,17]$. The use of cross-modal mappings in performance is

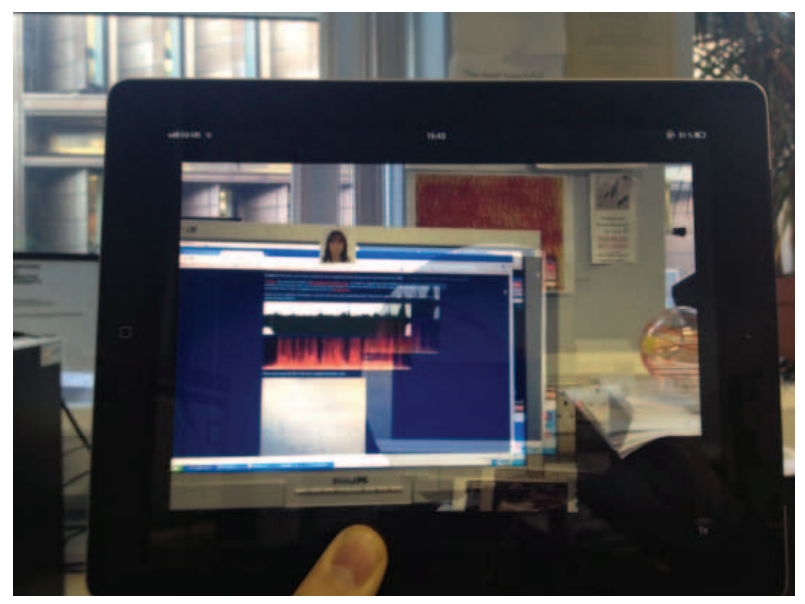

Fig. 2. Simulation of an afterimage created by touching near the centre of the iPad screen. The afterimage-here showing part of a computer screen-stays static while fading away over a few seconds. (๑) Alexis Kirke) another well-researched and explored area. Examples include Dance Jockey, which turns dance movements into music [18]; a system that allows dancers to manipulate visual simulations to create sound [19]; and the work of A. Tanaka on movement, biosignals and sound [20,21]. The initial purpose of the sonification in Insight was for use in performance and intended to draw attention to the hallucinations in order to make them seem more "real." However, such sonification may also be able to help people express their hallucinations helpfully in a multimodal way.

The AR application that we developed can be made to simulate hallucinations similar to the hallucinations Kirke sees. Whatever the iPad camera sees can be manipulated by using the iPad multi-touch screen. Among the effects that can be controlled is having groups of pixels randomly change to a fixed foreground color. When these pixels are combined with other elements related to palinopsia such as afterimages (Fig. 2) and trails, Kirke is able to create on the iPad screen a representation of the visuals he experiences. The application also includes a simple interface that allows the performer-Kirke in his performance as well as anyone to uses the application - to indicate where he is seeing patterns and images by touching the screen. Thus, during the performance the audience is able to see some semblance of what the performer is experiencing internally, in what is usually "private" vision. This expression of private visual states was the artistic motivation for the performance, but as time went on it became clear that many sufferers of hallucinations and others who care for them could benefit from having access to such a system.

\section{iPad Software Description}

The openFrameworks development platform has advanced image processing features that can be integrated into the iOS platform for mobile deployment. This allows the application made for the Insight performance to display a continuous video feed from the iPad's camera. The feed acts as input to the hallucination algorithms and provides a background layer to the hallucination effect layers, which are overlaid on top. This provides a real-time projection of a "reality layer" (what the camera is actually seeing) and hallucination effects, which are updated in relation to the video being displayed.

The hallucination controls are split into three modes that can overlap to create multiple layers of simulated hallucinations. These modes are defined by their methods of user control and their resultant visual and audio functions and effects. Modes are entered via display area-specific touch commands on the reality layer. This allows for a continuous reality layer on screen, avoiding the need for any navigation menus or buttons that may obstruct the audience's view of the projected mirrored display and distract the user from the hallucination experience. Mode-specific commands provide control for instigating and manipulating layers of simulated hallucinations. The three modes-single touch, multi-touch and visual echo-dictate the type of virtual hallucination that can be displayed. 


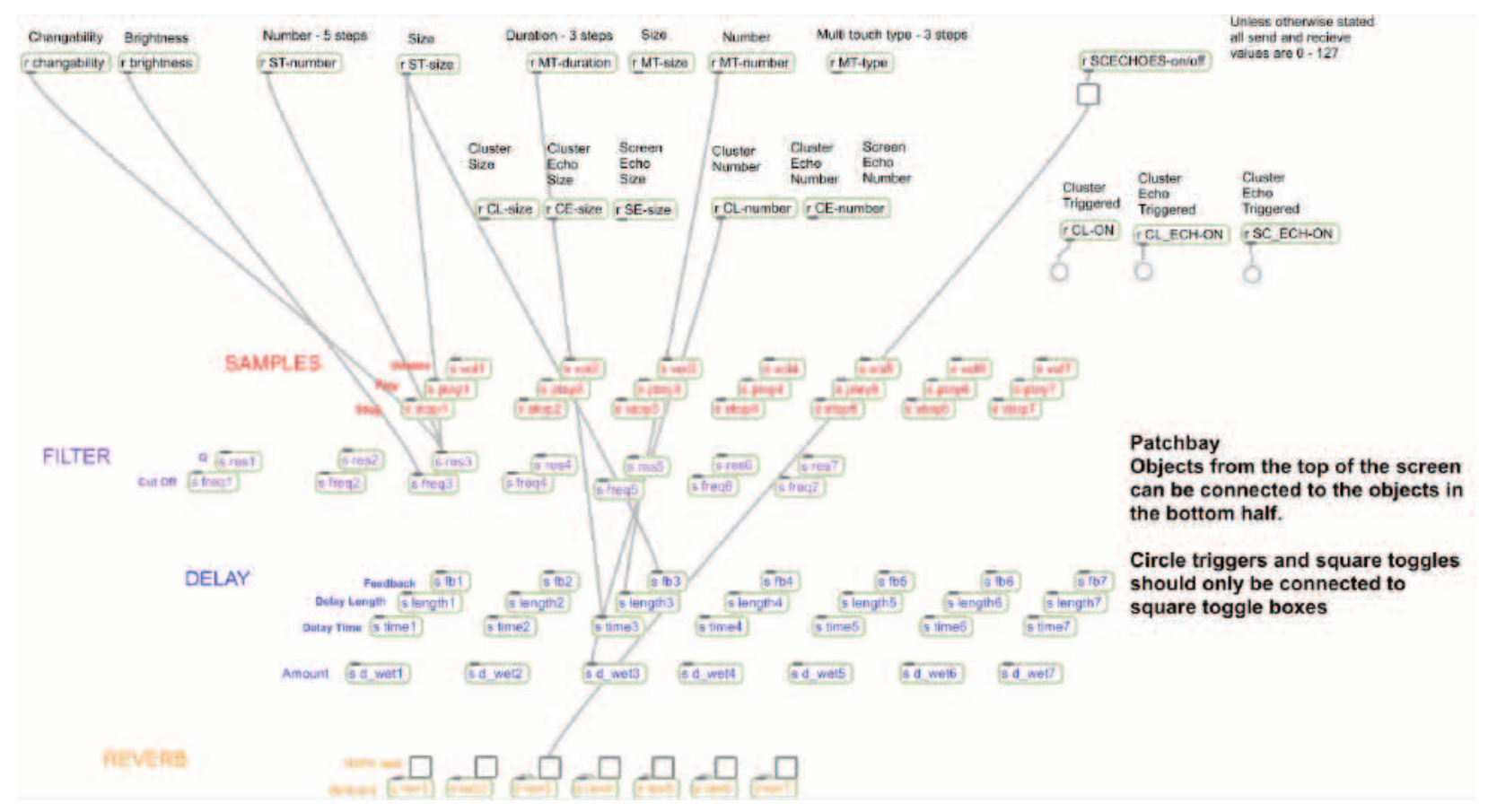

Fig. 3. Mappings available for visuals sonification. This Max patch demonstrates how visual parameters are mapped onto musical parameters. This example shows that the aftereffect size in single-touch mode is mapped to affect the volume of sound sample 2. (๑ Alexis Kirke)

Single-touch mode allows for an area of the video feed to be mapped onto an afterimage layer. The location of the user's touch dictates the on-screen position of the afterimage. The size of the afterimage is defined by the duration of the touch, and the on-screen duration of the afterimage is defined by the distance of a swipe movement after the initial touch command. Users can initiate and overlap multiple instances of single touch commands.

Commands in multi-touch mode generate clusters of small afterimage areas akin to stochastically arranged groups of circles. The cluster size and duration are, again, user-definable, whereas individual afterimage positioning within a cluster is fixed to a random ordering to mirror the randomness and blurring that occurs with palinopsia.

Within the visual echo mode the video input is processed and generates "echoes" of delayed images. This creates the effect of visual trails surrounding a moving object while motionless background content is unaffected. The user is able to control the speed of the echoes and the duration of the effect. The visual echo mode also features layers containing clusters of afterimages, triggered and still visible before any echoes have been initiated. The layers are also echo-affected and echo simultaneously with the primary visual trails.

The technical implications of a software algorithm designed to emulate states envisioned only by a subject of palinopsia offered a number of design and implementation issues. Successfully interpreting a neurological condition based upon text and conversation-based descriptions required considerable attention to detail, as development was undertaken using limited references. A descriptive framework defines one person's ultimate reality, so we needed to employ wide margins to allow for constant adjustment and refining.

\section{Laptop Software Description}

The performance's success lay in its communication of the visual effects of palinopsia to an audience. This allowed for experimentation in how the visual effects of the condition can be musified. A dynamic framework of mapping visual effects onto audio parameters allowed for the user to select controls based on aesthetic preference. This assisted in creating a more engaging experience for the audience, wherein the performance was true to the condition while also allowing for creative artistic interaction.

The Max patch provides six audio modules and a separate interface to act as a patchbay to allow the performer to design the mappings between the iPad visualizations and the musical parameters of the audio modules, and even to alter them during the performance. This patching approach (Fig. 3) highlights the black objects residing in the top half of the patch that receive data related to the onscreen activity from the iPad via Open Sound Control (OSC). These data streams can then be connected to the inputs of the musical parameters displayed in the various colors in the bottom half of the patch. These connect to the controls for the audio modules shown in Fig. 4. This setup provided a flexible platform for control during Kirke's performance, as mappings could be reassigned, removed or fixed, providing a richer creative palette for musical experimentation than systems with a fixed-point mapping system. 


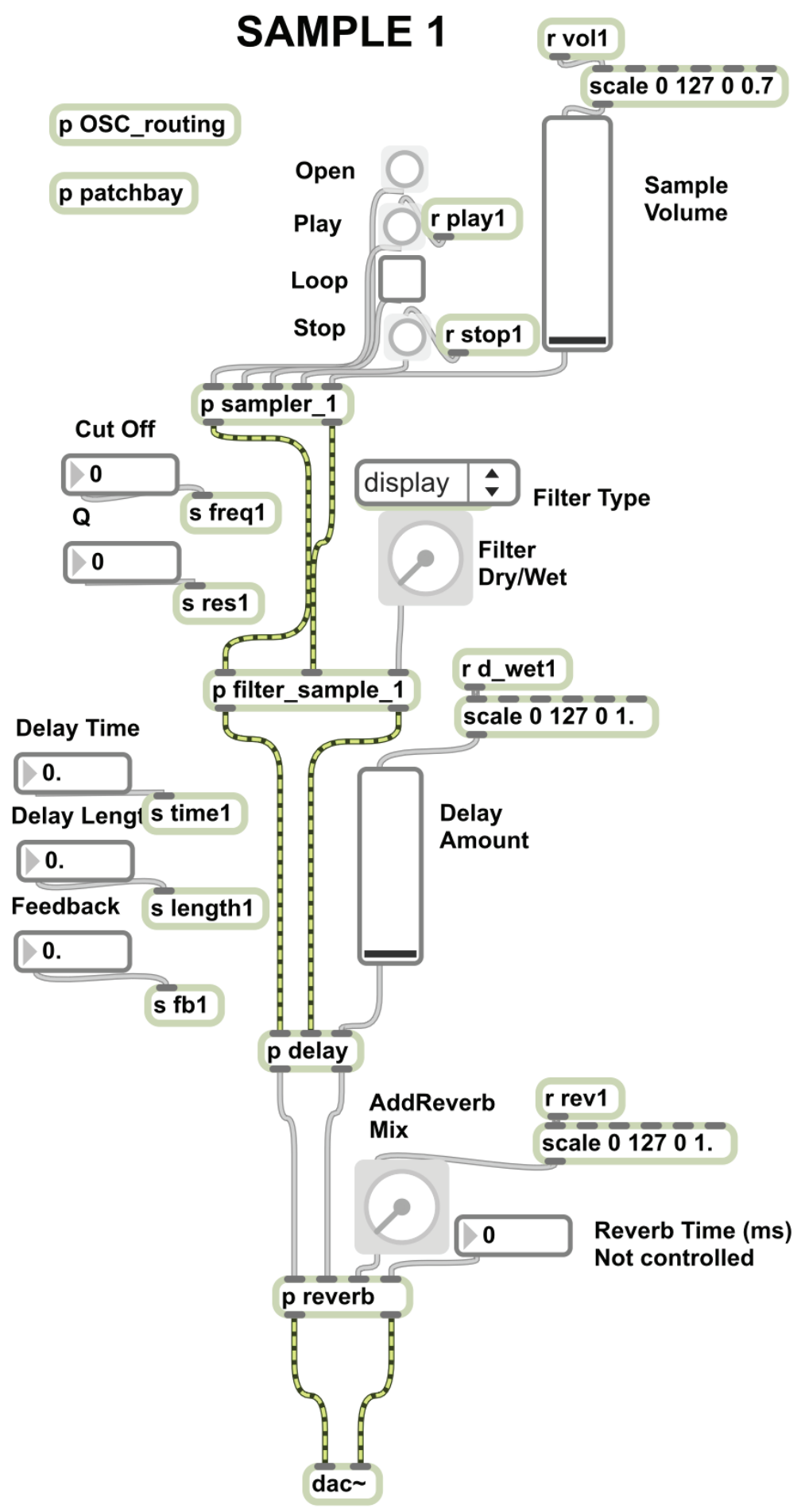

Fig. 4. One of the audio modules that comprises the electronic composition.

The parameters of the module receive their control signals from the iPad visuals via the user's configuration as specified in the patchbay shown in Fig. 3. (๑ Alexis Kirke)

The actual mappings for the performance were selected through experimentation by the composer. This involved a process of setting up potential MAX/MSP mappings using the patch (see Fig. 3) and trying them out in rehearsal and in the studio. The top half of Fig. 3 shows the various inputs from the iPad touchscreen-for example the brightness and variation on average across the screen or the size of the area over which an afterimage was switched on. These could be mapped onto the filter or effects parameters shown on the bottom half of Fig. 3. One of the most perceivable effects turned out to be the delays (outlined near the bottom of Fig. 3) between the appearance and disappearance of a visual-in particular as feedback loops built up. Levels of loudness were also significantly affected by the various visuals.

\section{SCORE DEVELOPMENT AND STRUCTURE}

The Insight performance score has three elements: a flute player, Kirke controlling electronics with his laptop and the Halluciphone, and lighting design controlled by an engineer offstage. The purpose of the lighting was to create a contrasting set of visuals for the Halluciphone. Kirke's motivation for selecting the flute was to make the performance more organic, as well as sonically and visually dynamic for the audience. The sound of the flute also has an element of ephemerality, which we felt captured the unreal feeling of the hallucinations. The flute score was in the idiom of contemporary classical music.

The first and third movements of the flute score were constructed using motifs quoting classical electronic dance music from the late 1980 ond 1990 . The second and third movements were written with some help from DJ Pierre, credited with developing the first acid house [22] bassline for the track "Acid Trax" as a member of the band Phuture. He sent us a bass track-only version of a higher tempo version of the bassline from "Acid Trax," which we used as raw material for electronics in the third movement. The second movement was actually loosely based on the approach taken in DJ Pierre's bassline in "Acid Trax." In acid house music, musicians often use filtering to change bassline characteristics; these are sometimes called "filter sweeps." The filter sweeps in the "Acid Trax" bassline are shown in Fig. 5. An excerpt from the second movement is shown in Fig. 6. The second movement was largely made up of the flute playing the repetitive bass loop from "Acid Trax." Parts of the flute line are played with notes having extended or reduced duration and loudness, reminiscent of the effect of filter sweeps.

The broader artistic implementation of the piece was envisioned as giving the flautist opportunities to use extended techniques and to improvise on some of the themes. We also wanted to structure the piece so as to introduce various visual and sonic elements gradually, leading to a climax in the finale. Each movement consists of a mostly pre-scored flute 


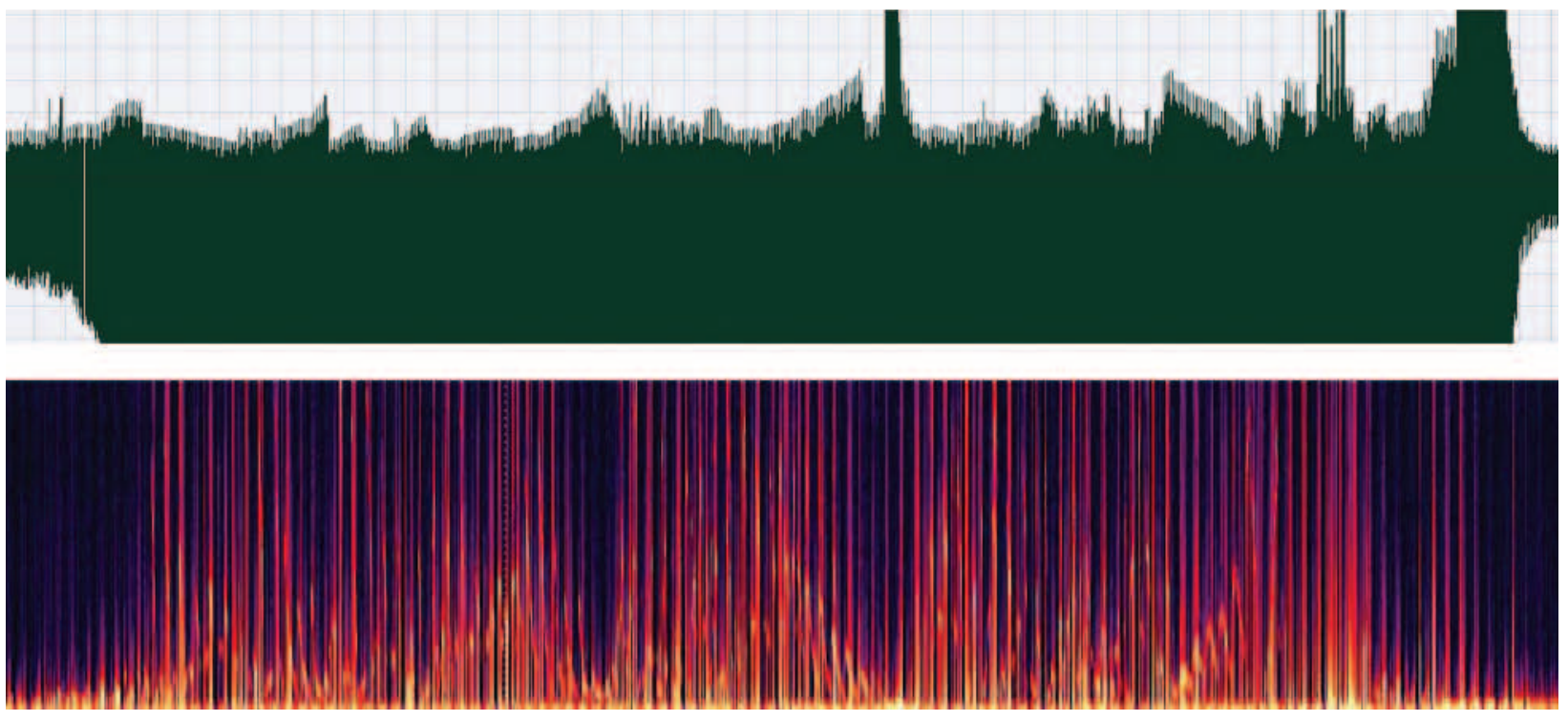

Fig. 5. (top) Waveform of the "Acid Trax" bassline; (bottom) spectrogram of filter sweeps. (๑ Alexis Kirke)
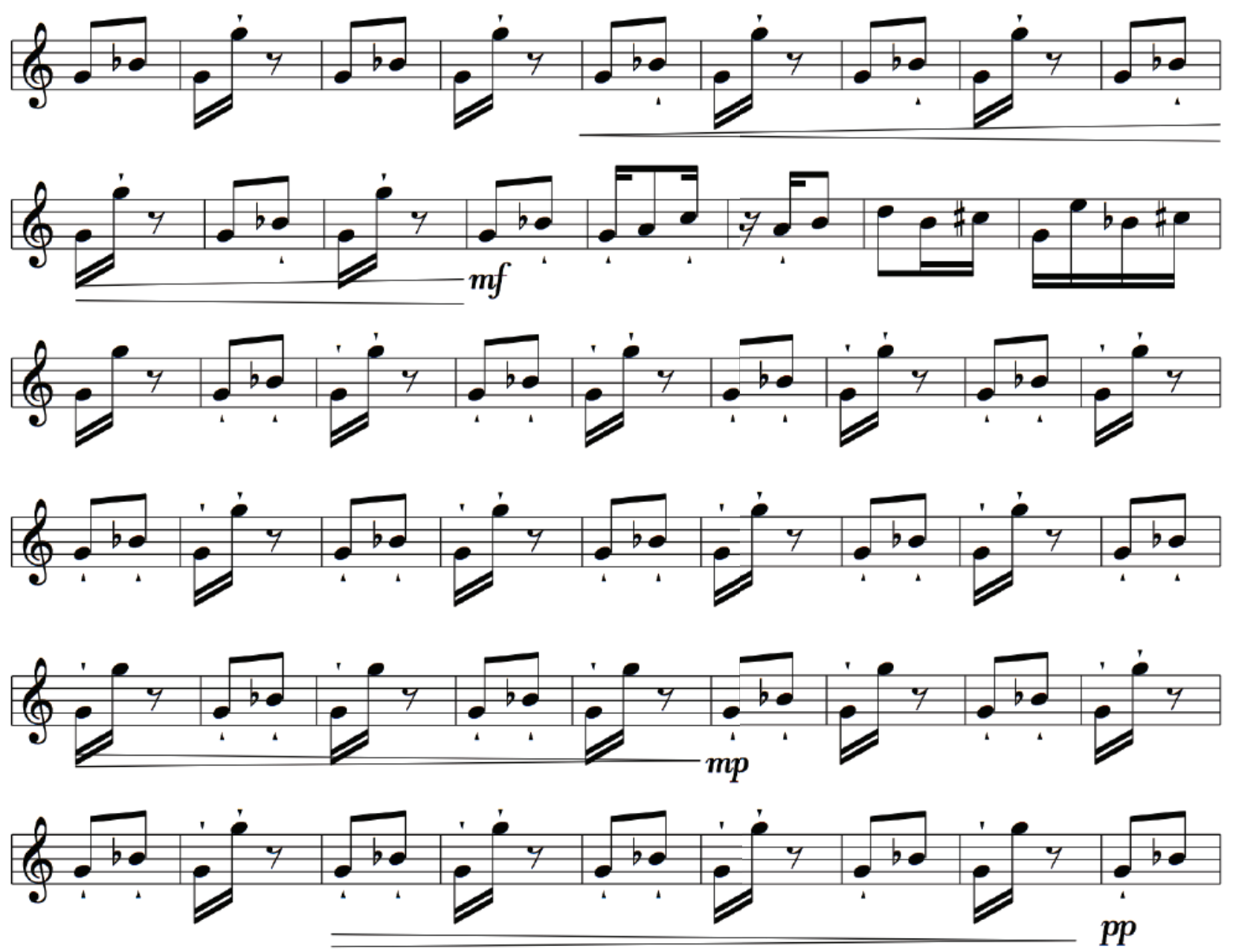

Fig. 6. Excerpt from the second movement from the score of Insight. (๑ Alexis Kirke) 


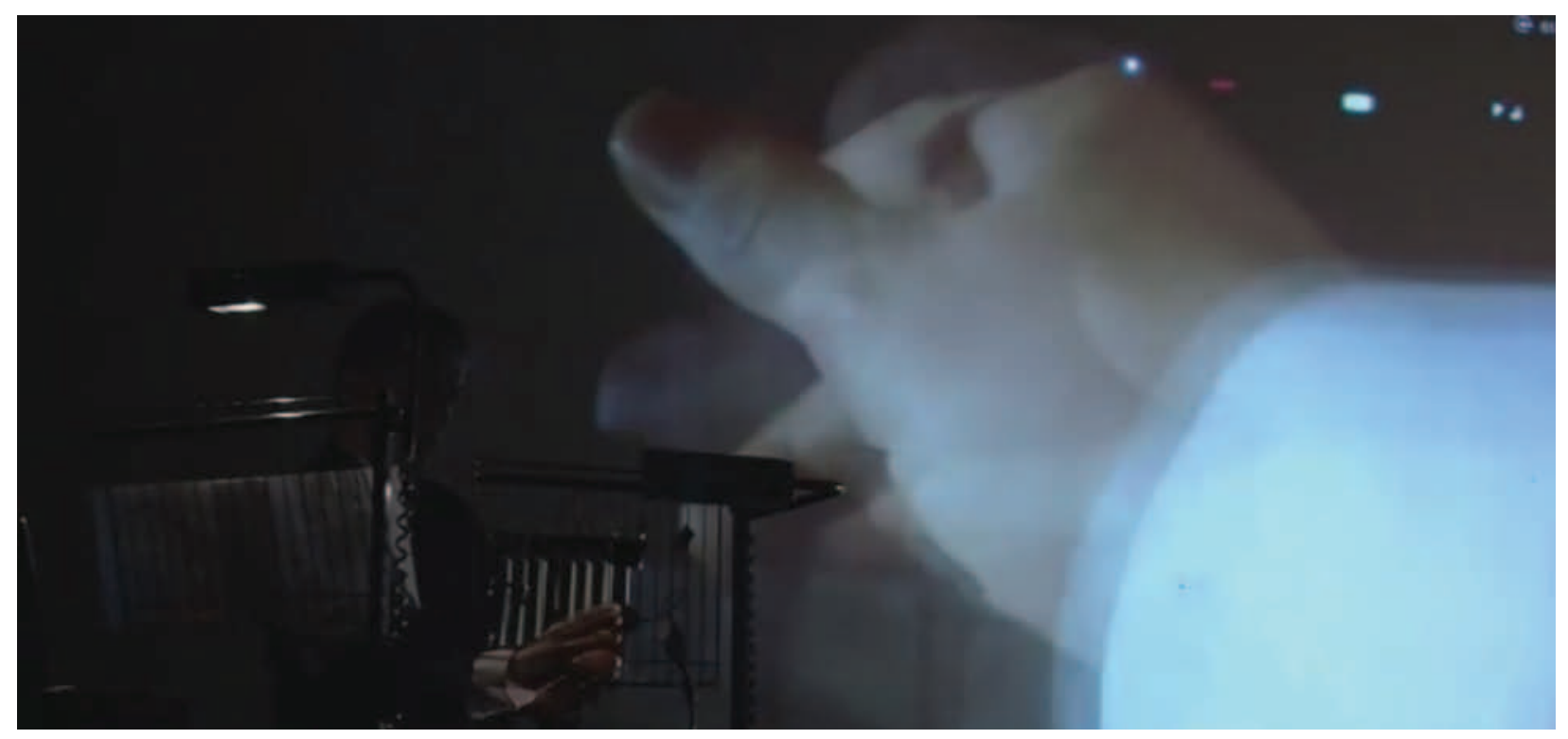

Fig. 7. Visual echo simulation during the performance premiere of Insight. The stage lighting illuminates a hand as it moves in front of the iPad camera, and the visual is projected onto the main screen. (๑ Alexis Kirke)

section, followed by an improvisational section. To create the desired arc for the flute, the flautist was instructed not to utilize any extended techniques until the third movement. The first movement involved a relatively normal contemporary classical flute score based on a number of themes from contemporary dance music. The second movement might be interpreted as minimalist but, as has already been stated, was more of an homage to the electronic dance music pioneers in the 1980s. Artistically, it is a form of "calm before the storm." The final movement is written to be more chaotic. It is made up of segments based on the themes from the first movement, but interspersed by a number of bars of improvised extended techniques. It ends with a vigorous improvisation from the flautist incorporating extended techniques.

The electronics utilized the audio provided by DJ Pierre, as well as simple sounds chosen by Kirke for aesthetic reasons. He also selected these sounds-comprised of binaural beats, sub-bass and white noise-because he found them hypnotic and believed they could therefore potentially help him to concentrate on any hallucinations he might experience. These sounds were loaded into three of the sample channels shown in Fig. 4. These electronics were manipulated by the Halluciphone signals' patch in Fig. 3.

The lighting was designed so as to give a variety of visual effects to both trigger and highlight hallucinations. The lights were controlled live by the lighting technician, who knew the score and timings and controlled the lighting live following a lighting score, part of which is shown in Table 1. For the first movement, the arc for the visuals was to focus on static afterimages; the focus in the second movement was on visual trails; and the focus in the final movement was to incorporate all hallucination effects. The lighting score reflected similar goals; the lighting was intended to intensify afterimages in the first movement, and a spotlight was trained on the performer's free hand in the second movement to draw atten- tion to the hand, which he moved rapidly in an attempt to generate visual trails. The final movement utilized both types of lighting. Figure 7 shows an example of the visual echoes effect, highlighted by the lighting.

TABLE 1. Part of the lighting score used in the Insight performance.

\begin{tabular}{|c|c|c|c|c|c|}
\hline Cue & $\begin{array}{l}\text { Track } \\
\text { time } \\
\text { (sec) }\end{array}$ & State & $\begin{array}{c}\text { Uptime } \\
\text { (sec) }\end{array}$ & $\begin{array}{c}\text { Previous } \\
\text { state } \\
\text { downtime } \\
\text { (sec) }\end{array}$ & $\begin{array}{l}\text { Dwell } \\
\text { time } \\
\text { (sec) }\end{array}$ \\
\hline 0.5 & 0 & Preset & & & \\
\hline 1 & 0 & Blackout & 0 & 0 & 30 \\
\hline 2 & 30 & Flute only & 8 & 5 & 35 \\
\hline 3 & 73 & & 8 & 5 & 15 \\
\hline 4 & 96 & & 8 & 5 & 16 \\
\hline 5 & 120 & $\begin{array}{l}\text { All audience } \\
\text { at } 45 \%\end{array}$ & 8 & 5 & 7 \\
\hline 6 & 135 & Just flute & 5 & 8 & 105 \\
\hline 7 & 248 & Just flute & 8 & 5 & 0 \\
\hline 8 & 262 & $\begin{array}{l}\text { Stage } \\
\text { flooded } \\
\text { with light }\end{array}$ & 1 & 0 & 1.5 \\
\hline 9 & & Just flute & 0 & 0 & 0 \\
\hline 10 & 284 & $\begin{array}{l}\text { Stage } \\
\text { flooded } \\
\text { with light }\end{array}$ & 1 & 0 & 1.5 \\
\hline 11 & & Just flute & 0 & 0 & 0 \\
\hline 12 & 305 & $\begin{array}{l}\text { Stage } \\
\text { flooded } \\
\text { with light }\end{array}$ & 1 & 0 & 1.5 \\
\hline
\end{tabular}

Etc... 


\section{FEEDBACK}

Because the project has so far been primarily developed specifically for the Insight performance, no formal results on the realism of the hallucination simulator have been reported. However, informal commentary from the Palinopsia Foundation and a number of sufferers of palinopsia provided initial feedback as well as motivation to extend the study into more formal realms.

The Palinopsia Foundation is currently using a video demo of the iPhone version of our software to introduce their webpage [23]. A link to a video of the Insight performance was placed on a forum frequented by people with symptoms of palinopsia [24]. The video received the following anonymous reply:

I have been suffering from these visuals for about 14 years now, its only been in last few months that ive been learning about palinopsia and also hppd, i felt relieved knowing there was a name for something $\mathrm{i}$ have been suffering with for many years and just thought $\mathrm{i}$ was going mad ... im really interested in talking to you i have just gone on the website you provided and was amazed by what you have done its exactly what i see.

This response shows that the performance itself can be an effective vehicle for educational purposes, as well as for raising awareness about the symptoms of palinopsia. The next three quoted messages were unsolicited public YouTube comments from people who watched a demo video of the hallucination simulator [25]:

hi, I watched your iphone/ipad hallucination software video. Never ever thought I would find anyone else with this condition. I too have been suffering with it for almost a year now. I don't experience the trails but definitely the afterimages.

I have had visual echoes for a month now and this is comforting that this isn't something much more serious.
Thank you so much for this video... it allowed me to show people i love what i see when i have palinopsia, which is quite hard to describe just with words. Thanks!!

The Insight performance premiered at Peninsula Arts Contemporary Music Festival 2012 at Plymouth University (U.K.). We found that the synthesizer at times suffered from feedback instability; this needs to be investigated. We also found that to create a sufficiently interesting performance the performer had to overemphasize the visual effects of palinopsia. However, when implementing this overemphasis, the performer found that the visual echoes and the afterimages in particular were often quite reasonable simulations, especially when the lighting score was implemented.

\section{CONCLUSIONS}

We have introduced a performance that highlights a new approach to hallucination simulation, allowing real-time audio and visual expression using an iPad. Our application, the Halluciphone, enables individuals to overlay simulations of their hallucinations in real time on the iPad screen over the iPad's video camera image. This approach could also be utilized to simulate other conditions and visual hallucination types. The system also made use of visuals sonification to allow hallucinations to be converted into sound. Insight, the musical performance for which the Halluciphone was initially developed, has helped to raise awareness of palinopsia and comfort some people who have symptoms of palinopsia. Because the project has so far primarily been performancebased, we have yet to gather formal results on the usage of the system as a hallucination simulator. However, the feedback we received from the Palinopsia Foundation and a number of individuals who suffer from palinopsia has provided us with insight into the potential of this project and motivated us to extend the study into more formal realms.

\section{References and Notes}

Unedited references as provided by the authors.

1 H. Pomeranz and S. Lessell, "Palinopsia and polyopia in the absence of drugs or cerebral disease," Neurology, Vol. 54, No. 4 (2000) p. 855.

2 S. Van der Stigchel, T. Nijboer, D. Bergsma, J. Barton and C. Paffen, "Measuring palinopsia: Characteristics of a persevering visual sensation from cerebral pathology," Journal of Neurological Sciences, Vol. 316, No. 1-2 (2012) p. 184.

3 K. Edgar, Personal Communication with Oliver Sacks' Personal Assistant and Editor (16 Jan 2012).

4 D. Kömpf, H. Piper, B. Neundörfer and H. Dietrich, "Palinopsia (visual preservation) and cerebral polyopia-Clinical analysis and computed tomographic findings," Fortschritte der NeurologiePsychiatrie, Vol. 51, No. 8 (1983) p. 270.

5 S. Van der Stigchel et al. [2].

6 J. Dubois and R. VanRullen, "Visual Trails: Do the Doors of Perception Open Periodically?" PLoS Biology, Vol. 9, No. 5 (2011).

7 O. Sacks, Hallucinations (New York, NY: Alfred A. Knopf, 2012).

8 S. Brown, "Implementing a Brief Hallucination Simulation as a Mental Illness Stigma Reduction Strategy," Community Mental Health Journal, Vol. 46, No. 5 (2010) p. 500.

9 F. Mantovani, G. Castelnuovo, A. Gaggioli and G. Riva, "Virtual Reality Training for Health-Care Professionals," CyberPsychology \& Behavior Vol. 6, No. 4 (2003) p. 389.

10 D. Van Krevelen and R. Poelman, "A Survey of Augmented Reality Technologies, Applications and Limitations," Journal of Virtual Reality, Vol. 9, No. 2 (2010) p. 1.

11 T.N. Arvanitis, A. Petrou, J.F. Knight, S. Savas, S. Sotiriou, M. Gargalakos, E. Gialouri, "Human factors and qualitative pedagogical evaluation of a mobile augmented reality system for science education used by learners with physical disabilities," Personal and Ubiquitous Computing, Vol. 13, No. 3 (2009) p. 243.

12 E. Richard, V. Billaudeau, P. Richard, G. Gaudin, "Augmented Reality for Rehabilitation of Cognitive Disabled Children: A Preliminary Study" in Proceedings of the Virtual Rehabilitation Conference, Venice, Italy (2007) p. 102.

13 A. Helal, S.E. Moore, B. Ramachandran, "Drishti: An Integrated Navigation System for Visually Impaired and Disabled," in Proceed- 
ings of the Fifth International Symposium on Wearable Computers, Zurich, Switzerland (2001) p. 149.

14 J. Clemons, Y. Bao, M. Bagra, T. Austin and S. Savarese, "Scene Understanding for the Visually Impaired Using Visual Sonification by Visual Feature Analysis and Auditory Signatures," Journal of Vision, Vol. 12, No. 9 (2012).

15 M. Bujacz, P. Skulimowski and P. Strumillo, "Sonification of $3 \mathrm{D}$ scenes using personalized spatial audio to aid visually impaired persons," in Proceedings of the International Conference on Auditory Display, Budapest, Hungary (2011).

16 C. Giller, A. Murro, Y. Park, S. Strickland and J. Smith, "EEG Sonification for Epilepsy Surgery: A Clinical Work-In Progress," in Proceedings of the International Conference on Auditory Display, Atlanta, GA (2012).

17 T. Kagawa, H. Kudo, S. Tanoue, H. Mori, H. Nishino and K. Utsumiya, "A Supporting Method of Medical Imaging Diagnosis with Sonification," in Proceedings of the Conference on Complex, Intelligent and Software Intensive Systems, Palermo, Italy (2012) p. 699.

18 Y. de Quay, R. Frias, S. Skogstad and A. Jensenius, "Dance Jockey: Performing Electronic Music by Dancing," Leonardo Music Journal, Vol. 21 (2011) p. 11.

19 A. Johnston, "Fluid Simulation as Full Body Audio-Visual Instrument," in Proceedings of the Conference on New Interfaces for Musical Expressions, Daejeon, South Korea (2013) p. 132.

20 A. Tanaka, "The Sound of Photographic Image" AI \& Society, Vol. 27, No. 2 (2012).

21 A. Tanaka, "Mapping Out Instruments, Affordances, and Mobiles," in Proceedings of the Conference on New Interfaces for Musical Expression, Sydney, Australia (2010) p. 88.

22 P. Blashill, "Six Machines That Changed the Music World," Wired Magazine, 10.05 (2002).

23 See the video on the Palinopsia home page: <www.palinopsiafoun dation.org >.

24 The video of the Insight performance that the anonymous poster refers to is available at: $\langle$ www.youtube.com/watch? $\mathrm{v}=\mathrm{a} 5 \mathrm{CKUkDyR} 1 \mathrm{U}\rangle$. The palinopsia forum can be found at: <www.steadyhealth.com/ Palinopsia_t74784.html>.

25 The full video and comments are available for viewing at: $<w w w$. youtube.com/watch? $\mathrm{v}=\mathrm{ccPpezbdVis>}$.

Manuscript received 7 August 2013.

ALEXIS KIRKE is a senior research fellow at Plymouth University's Interdisciplinary Centre for Computer Music Research. He is also a composer well known for his interdisciplinary practice.

JOEL EATON is a creative developer, musician and Ph.D. student at the Interdisciplinary Centre for Computer Music Research at Plymouth University.

EDUARDO MIRANDA is a professor of Computer Music at Plymouth University. He leads the University's Interdisciplinary Centre for Computer Music Research.

\section{Leonardo Art Science Evening Rendezvous (LASER)}

Since 2008, the Leonardo Art Science Evening Rendezvous (LASER) series of lectures and presentations on art, science and technology has provided spaces for progressive thought leaders to come together to form community and explore the intersections of disciplinary thinking. Owing to its success and popularity, LASER has expanded beyond its birthplace in the San Francisco Bay Area, first to the U.S. East Coast, then across the Atlantic to London - the home of the first European LASER - and today continues to expand to new locations nationally and internationally. We thank all of those who have spoken at, participated in or attended LASER events throughout the years. We owe a special thank you to Piero Scaruffi, LASER founder and chair, for his inspiration and continued dedication, and to the growing list of LASER hosts around the world. To follow LASER events, see <www.leonardo.info/isast/laser.html>. 


\section{Leonardo/ACM SIGGRAPH Special Issue Featuring SIGGRAPH 2015 Art Papers and Hybrid Craft @ SIGGRAPH 2015 Art Gallery}

We are pleased to announce this year's forthcoming SIGGRAPH 2015 special issue of Leonardo, presented in collaboration with SIGGRAPH 2015. The issue will feature SIGGRAPH 2015 Art Papers and visual documentation of the works exhibited in the SIGGRAPH 2015 Hybrid Craft @ SIGGRAPH 2015 Art Gallery.

The SIGGRAPH 2015 issue of Leonardo features not only artists and artwork, but also the processes and theoretical frameworks for making art and contextualizing its place in society. Art Papers explore the changing roles of artists and the methods of art-making in our increasingly networked and computationally mediated world, present excellent ideas in accessible ways, inform artistic disciplines, set standards and stimulate future trends.

The theme of the SIGGRAPH 2015 Art Gallery is Hybrid Craft, a showcase of craft techniques and values in contemporary digital design, such as digital technologies and hand-hewn craft, computer-aided design and manual tools, 3D printing and traditional carving, or digital signal-processing and traditional acoustic instruments. The gallery works demonstrate a multi-directional exchange of knowledge between the new and the traditional, as well as visualize techniques to protect and preserve traditional practices. The gallery emphasizes the importance of craft heritage in contemporary digital design, where beautiful and meaningful artifacts are produced by machine and craftsperson together, not by a machine or by a craftsperson alone.

Publication of the special issue, Leonardo Volume 48, Issue 4 (July 2015), will coincide with SIGGRAPH 2015, the 42nd International Conference and Exhibition on Computer Graphics and Interactive Techniques, Los Angeles Convention Center, 9-13 August 2015. 